\title{
Mechanisms Behind the Increased Vulnerability of the Aging Stomach to NSAID-Related Injury: Perhaps Not As Simple As We May Think
}

\author{
Raymond S. Tang $\cdot$ Francis K. L. Chan
}

Published online: 20 October 2012

(c) Springer Science+Business Media New York 2012

Non-steroidal anti-inflammatory drugs (NSAIDs) are frequently prescribed to treat conditions such as arthritis and other musculoskeletal disorders in elderly patients. The usefulness of NSAIDs is, however, often limited by their associated gastrointestinal (GI) toxicity [1, 2]. Elderly patients taking long-term NSAIDs therapy are a particularly high-risk group for NSAIDs-related GI injury [3, 4].

NSAIDs-related GI injury is mainly a consequence of systemic inhibition of GI mucosal cyclooxygenase (COX) activity, which reduces levels of mucosa-protective prostaglandins (PG), for example prostaglandin $\mathrm{E}_{2}$ (PGE2), rather than a result of topical epithelial injury [5-7]. Inhibition of the two isozymes of COX, COX-1 and COX-2, is important in the pathogenesis of NSAIDs-related gastric injury [6]. COX-1 is a constitutive enzyme expressed in most cells of the body, including the stomach [6]. In contrast, COX-2 is an inducible enzyme, with increased expression in response to bacterial polysaccharides and proinflammatory cytokines [6]. Although non-selective NSAIDs (e.g., indomethacin) exert their GI ulcerogenic effects mainly through COX-1 inhibition, the GI ulcerogenic effects of NSAIDs require inhibition of both COX-1 and COX-2 [7, 8]. Mucosa-protective PGs (e.g., $\mathrm{PGE}_{2}$ ) contribute to gastric mucosal

R. S. Tang $(\bowtie)$

Department of Medicine and Therapeutics, Prince of Wales Hospital, The Chinese University of Hong Kong, Room 94020, 7/F, Clinical Science Building, Shatin, New Territories,

Hong Kong

e-mail: rtang01@yahoo.com

\section{F. K. L. Chan}

Institute of Digestive Disease, Prince of Wales Hospital,

The Chinese University of Hong Kong, 30-32 Ngan Shing Street,

Shatin, New Territories, Hong Kong

e-mail: fklchan@cuhk.edu.hk defense by reducing gastric acid secretion and by their nonantisecretory effects referred to as "cytoprotection" (e.g., stimulation of bicarbonate and glycoprotein secretion, increase in mucosal blood flow, among others) [9, 10]. It has been suggested that nitric oxide (NO) is the crucial intermediate in $\mathrm{PGE}_{2}$-mediated cytoprotection [11]. Hence, deficiency in mucosa-protective PGs or NO because of NSAIDs use is associated with compromise of gastric mucosal defense. Mechanisms independent of COX inhibition are also implicated in NSAIDs-related gastric injury. NSAIDs may also produce gastric mucosal injury by interfering with growth factors (e.g., TGF- $\beta$, TGF- $\alpha$ ) and other mediators responsible for epithelial restitution and adaptive protection (e.g., trefoil family peptides) [12, 13]. Reactive oxygen species and apoptosis are also implicated in indomethacin-induced gastric injury [14].

Why aging stomachs are at greater risk of NSAIDsrelated injury is still poorly understood. Data from outcome studies have identified advanced age as one of the major risk factors for NSAIDs-related upper GI injury [1], possibly because of the finding that the aging gastric mucosa has reduced capacity for repair. A recent study investigating the effect of reactive oxygen species, apoptosis, and angiogenesis on the aging stomach has shown that aging gastric mucosa is gradually replaced by connective tissue, thus impairing gastric mucosal protection [15]. In rats of advanced age, angiogenesis is reduced as a result of reduced expression of VEGF and overexpression of PTEN [16]. Thus, reduction in mucosal defense mechanisms characteristic of the aging stomach may increase susceptibility to NSAIDs-related mucosal injury, although the underlying molecular pathogenesis remains poorly understood.

In this issue of Digestive Diseases and Sciences, Hong et al. [17] report investigation of potential molecular mechanisms behind the increased susceptibility of the 
aging stomach to indomethacin-induced injury. The authors hypothesize that upregulation of pro-inflammatory mediators in old stomachs increases their susceptibility to indomethacin-induced injury compared with young stomachs. When the same oral dose of indomethacin was administered to young (6 weeks) and old (60 weeks) rats, significantly greater gastric mucosal damage was observed in old rat stomachs. Before administration of indomethacin, levels of several inflammatory mediators (COX-2, iNOS, HIF- $1 \alpha$, and 5-LOX), inflammatory cytokines (TNF- $\alpha$, IL$1 \beta$, IL-6, IL-8, and IFN- $\gamma$ ), inflammatory chemokines (MIP-1 $\alpha$, MIP-1 $\beta$, MCP-1, and RANTES), adhesion molecules (ICAM-1, VCAM-1, and VGEF), proteases (MMP2 and MMP-9), total oxidants, and apoptotic executors (caspase-3 Bax) were already significantly higher in the stomachs of old rats; these levels were further increased after indomethacin administration. The authors concluded that redox activation and an increase in pro-inflammatory mediators are likely mechanisms behind the increased vulnerability of aging stomachs to NSAIDs-related injury.

Yet, this study also reported findings that challenge our current belief that $\mathrm{PGE}_{2}$ deficiency is the main cause of NSAIDs-related gastric injury. In particular, initially, i.e. before administration of indomethacin, Hong et al. found no difference between $\mathrm{PGE}_{2}$ levels in young and old rat stomachs; subsequently, i.e. after indomethacin administration, they observed a significant increase in $\mathrm{PGE}_{2}$ levels in old rat stomachs. How can we explain these discrepancies? For the first finding, perhaps the actual decline in age-related gastric mucosal defense may not be entirely $\mathrm{PGE}_{2}$-dependent. It is possible that additional events (e.g., replacement of mucosal tissue by connective tissue and reduced angiogenesis) may be more important in the impaired mucosal defense of aging stomachs $[15,16]$. For the second finding, the increase in $\mathrm{PGE}_{2}$ level may be related to the known observation of upregulation of COX-2 expression after NSAIDs-related inhibition of COX-1 [18]. Moreover, the increase in $\mathrm{PGE}_{2}$ $12 \mathrm{~h}$ after indomethacin administration may be a transient phenomenon in the dynamic process of NSAIDs-related gastric injury. Whether or not persistent elevation of $\mathrm{PGE}_{2}$ level occurs has not been addressed. Further research is needed to resolve some of the uncertainties raised by this study and to better elucidate the actual sequence of molecular events in NSAIDs-related gastric injury.

\section{References}

1. Lanza FL, Chan FK, Quigley EM, et al. Guidelines for prevention of NSAID-related ulcer complications. Am J Gastroenterol. 2009;104:728-738.
2. Soll AH, Weinstein WM, Kurata J, et al. Nonsteroidal antiinflammatory drugs and peptic ulcer disease. Ann Intern Med. 1991;114:307-319.

3. Silverstein FE, Faich G, Goldstein JL, et al. Gastrointestinal toxicity with celecoxib vs. nonsteroidal anti-inflammatory drugs for osteoarthritis and rheumatoid arthritis: the CLASS study: a randomized controlled trial. Celecoxib long-term arthritis safety study. JAMA. 2000;284:1247-1255.

4. Griffin MR, Piper JM, Daugherty JR, et al. Nonsteroidal antiinflammatory drug use and increased risk for peptic ulcer disease in elderly persons. Ann Intern Med. 1991;114:257-263.

5. van Oijen MG, Dieleman JP, Laheij RJ, et al. Peptic ulcerations are related to systemic rather than local effects of low-dose aspirin. Clin Gastroenterol Hepatol. 2008;6:309-313.

6. Takeuchi K. Pathogenesis of NSAID-induced gastric damage: importance of cyclooxygenase inhibition and gastric hypermotility. World J Gastroenterol. 2012;18:2147-2160.

7. Wallace JL, McKnight W, Reuter BK, et al. NSAID-induced gastric damage in rats: requirement for inhibition of both cyclooxygenase 1 and 2. Gastroenterology. 2000;119:706-714.

8. Tanaka A, Araki H, Komoike Y, et al. Inhibition of both COX-1 and COX-2 is required for development of gastric damage in response to nonsteroidal antiinflammatory drugs. $J$ Physiol Paris. 2001;95:21-27.

9. Robert A, Nezamis JE, Lancaster C, et al. Cytoprotection by prostaglandins in rats. Prevention of gastric necrosis produced by alcohol, $\mathrm{HCl}, \mathrm{NaOH}$, hypertonic $\mathrm{NaCl}$, and thermal injury. Gastroenterology. 1979;77:433-443.

10. Takeuchi K, Kita K, Hayashi S, et al. Regulatory mechanism of duodenal bicarbonate secretion: roles of endogenous prostaglandins and nitric oxide. Pharmacol Ther. 2011;130:59-70.

11. Jiménez D, Martin MJ, Pozo D, et al. Mechanisms involved in protection afforded by L-arginine in ibuprofen-induced gastric damage: role of nitric oxide and prostaglandins. Dig Dis Sci. 2002;47:44-53.

12. Kato K, Chen MC, Nguyen M, et al. Effects of growth factors and trefoil peptides on migration and replication in primary oxyntic cultures. Am J Physiol. 1999;276:G1105-G1116.

13. Babyatsky MW, deBeaumont M, Thim L, et al. Oral trefoil peptides protect against ethanol- and indomethacin-induced gastric injury in rats. Gastroenterology. 1996;110:489-497.

14. Naito Y, Yoshikawa T. Oxidative stress involvement and gene expression in indomethacin-induced gastropathy. Redox Rep. 2006;11:243-253.

15. Kang JM, Kim N, Kim JH, et al. Effect of aging on gastric mucosal defense mechanisms: ROS, apoptosis, angiogenesis, and sensory neurons. Am J Physiol Gastrointest Liver Physiol. 2010; 299:G1147-G1153.

16. Huang J, Kontos CD. PTEN modulates vascular endothelial growth factor mediated signaling and angiogenic effects. $J$ Biol Chem. 2002;277:10760-10766.

17. Hong H, Kim EH, Lee HJ, et al. Molecular mechanisms elucidating why old stomach is more vulnerable to indomethacininduced damage than young stomach. Dig Dis Sci. 2012 (Epub ahead of print). doi:10.1007/s10620-012-2314-1.

18. Tanaka A, Araki H, Hase S, et al. Up-regulation of COX-2 by inhibition of COX-1 in the rat: a key to NSAID-induced gastric injury. Aliment Pharmacol Ther. 2002;16:90-101. 